\title{
A INSERÇÃO DOS COMPLEXOS PRISIONAIS NO BRASIL NA PERSPECTIVA DAS CIDADES SUSTENTÁVEIS
}

\section{Marcelo Coelho Souza ${ }^{1}$ Maria Cláudia da Silva Antunes de Souza ${ }^{2}$}

RESUMO: É de conhecimento o tema emergente relacionado as cidades sustentáveis, entretanto, há poucos estudos sobre a inserção dos complexos prisionais no desenho urbano. Entende-se que a desarmonia entre as políticas públicas e penitenciária precisam se reinventar para que os complexos prisionais brasileiros, com a terceira maior massa carcerária, sejam inseridos nos espaços urbanos contribuindo de forma significativa com as cidades sustentáveis. Nesse contexto, objetiva-se discorrer sobre os complexos penitenciários no contexto das cidades sustentáveis, mostrando algumas ações no Brasil e no mundo. Destarte, utilizou-se do método indutivo no que se refere à metodologia, com base em reconhecidas obras doutrinárias.

Palavras-chave: Sustentabilidade, Espaços Urbanos, Penitenciárias, Sociedade Urbana, Prisionização Secundária.

\section{THE INSERTION OF PRISON COMPLEXES IN BRAZIL IN THE PERSPECTIVE OF SUSTAINABLE CITIES}

ABSTRACT: The emerging theme related to sustainable cities is well known, however, there are few studies on the insertion of prison complexes in urban design. It is understood that the disharmony between public and penitentiary policies needs to be reinvented so that Brazilian prison complexes, with the third largest prison mass, are inserted in urban spaces, contributing significantly to sustainable cities. In this context, this study discusses prison complexes in the context of sustainable cities, showing some actions in Brazil and in the world. Thus, we used the inductive method with regard to the methodology, based on recognized doctrinal works.

Keywords: Sustainability, Urban Spaces, Penitentiaries, Urban Society, Secondary Prison.

\section{INTRODUÇÃO}

As cidades tiveram seu início entre cinco a quinze mil anos atrás, as quais foram idealizadas por Platão no contexto de uma cidade ideal ${ }^{3}$. Evoluções ocorreram até o século 21

\footnotetext{
${ }^{1}$ Doutorando do PPCJ e Mestre em Gestão de Políticas Públicas, ambos pela UNIVALI. Especialista em Políticas e Gestão em Segurança Pública pela Faculdade Estácio de Sá. E-mail - marcelocoelho@sap.sc.gov.br.

${ }^{2}$ Doutora e Mestre em Derecho Ambiental y Sostenibilidad -Universidade de Alicante, Espanha. Mestre em Ciência Jurídica - UNIVALI. Professora Permanente no Programa de Pós-Graduação Stricto Sensu em Ciência Jurídica- UNIVALI.

${ }^{3}$ A obra "A República foi provavelmente escrita por volta de 375 a.C., quando Platão estava com pouco mais de 50 anos (ele era um aristocrata ateniense nascido em torno de 428 a.C. e morto em 347 a.C.)". (BLACKBURN. 2008).
} 
com características que foram se alterando no decorrer dos séculos. Suas dinâmicas e complexidades que envolvem o tecido social geram uma disfunção que percorre os assentamentos, relações humanas, questões ambientais, entre outros. Estas questões tornam-se necessárias em sua resolução, almejando o ponto de partida na transformação das cidades em sustentáveis.

Todavia, atingir as cidades sustentáveis passa por questões complexas e dinâmicas neste século como já descrito, visto que a promoção do bem-estar comum, sustentabilidade, questões socias e econômicas além de outros fatores geradores, não se encaixam no mundo globalizado permeado por paradigmas competitivos, pois capital e ecologia em muitos contextos são discrepantes.

O complexo fenômeno urbano denominado cidade se traduz em um ambiente onde a vida, com suas potencialidades, conflitos e demandas acontece. Centro da civilização contemporânea e da Sociedade Civil, adveio o modelo atual de uma infinidade e diversidade de influências culturais, onde a configuração urbana foi sendo aos poucos delineada e aperfeiçoada (SOUZA; ALBINO. 2018).

Neste sentido, com as estruturas abaladas, a sociedade além de se intensificar tornase mais complexa e dinâmica no decorrer dos tempos, fazendo com que a sociedade urbana e o urbano fiquem cada vez mais contraditórias e dolorosas, agredindo cada vez mais o tecido social. Este esgarçamento da sociedade moderna causada pelas influencias de uma sociedade líquida são agravadas pelo aprofundamento dos fenômenos sociais juntamente com a desigualdade de renda e crescimento econômico. (LEFEBVRE, 2006, p.84).

Por este motivo, o problema da pesquisa é: como reinventar ou construir cidades que visem, além das estruturas arquitetônicas e da sustentabilidade social, os aspectos relacionais nos espaços urbanos, equalizando o crescimento e a modernidade estrutural das cidades e a necessidade de sua adequação ao bem-estar da coletividade, o convívio social, a diminuição das desigualdades, exclusão social e, especialmente, os complexos penitenciários?

Entretanto, a justificativa desta pesquisa residiu na percepção das dificuldades para serem atingidos concomitantemente o equilíbrio econômico e social, onde a existência de políticas e gestão públicas, assim como direcionamento preciso de recursos financeiros garanta direitos e princípios fundamentais, como moradia, dignidade e cidadania.

Derivado deste processo tem-se o crescimento das cidades e consequentemente um aumento considerável da pobreza, trazendo graves problemas socioambientais oriundos da 
ausência estatal. O sucateamento das instituições infere não somente nas questões sociais, mas também na crise da cidade em decorrência da falta de maciços investimentos em infraestrutura e saneamento. Desta maneira, com os problemas apresentados acima, surge uma nova organização espacial das classes sociais, confinadas pela segregação social gerada pela elite que controla e produz o espaço urbano.

Destarte, desta somatização tem-se o aprisionamento elevado das classes mais pobres, tornando o Brasil a $3^{\mathrm{a}}$ maior massa carcerária no mundo. Esta população que se encontra nos complexos prisionais do Brasil, além de encontrar-se na maioria das vezes com seus direitos violados, contribuem significativamente para a adversidade que agravam a crise da cidade e a degradação do tecido social.

Assim, o objetivo é analisar a inserção dos complexos prisionais no Brasil na perspectiva das cidades sustentáveis, em virtude da desestruturação da cidade que evidencia a profundidade dos fenômenos de desintegração. Neste prisma, a questão da inserção das estruturas prisionais dentro das cidades sustentáveis vai além do tecido urbano, atingindo as esferas das políticas públicas, redução dos índices de violência urbana, relação jurídica entre Estado e preso, planejamento urbano, sociedade, reinserção do apenado no meio social, questões de estruturas prisionais sustentáveis (com a utilização de painéis fotovoltaicos, reaproveitamento de água, plantação de verduras e hortaliças, utilização de jardins filtrantes, compostagem, etc.), entre outras situações. Destaca-se que muitos itens citados nas estruturas prisionais já se encontram em funcionamento nas penitenciárias de Santa Catarina ${ }^{4}$. Enfatizase que se trata de uma complexidade que não se limita apenas a estrutura física e sua localização geográfica no espaço urbano sustentável.

Em suma, o tema central desta pesquisa versa sobre a desarmonia entre as políticas públicas e o sistema prisional precisam se reinventar para que os complexos prisionais sejam inseridos de forma planejada nos espaços urbanos contribuindo de forma significativa com as cidades sustentáveis. Muitas soluções já se encontram em atividade em Santa Catarina, porém de formas dispersas no Estado e sem políticas públicas para seu fomento. Nesse contexto, o

\footnotetext{
${ }^{4}$ As boas práticas sustentáveis feitas pelo governo do Estado de Santa Catarina, podem ser verificadas no site www.sap.sc.gov.br. Tem-se apresentado pela Secretaria de Administração Prisional e Socioeducativa inúmeras soluções inovadoras dentro dos cárceres, que vão desde plantação de verduras na penitenciária de Chapecó, feira de produtos agrícolas à comunidade juntamente com compostagem e plantação da uva-bordô em Curitibanos, captação da água da chuva no Complexo Prisional de Canhanduba - Itajaí, a substituição de copos descartáveis por reutilizáveis para os servidores das unidades prisionais, cultivo de hortifrúti na região de Rio do Sul entre outros.
} 
presente estudo discorre sobre os complexos penitenciários no contexto das cidades sustentáveis, mostrando algumas ações no Brasil e no mundo., as quais são pouco exploradas na literatura. Visando contribuir com um tema tão emergente como o das cidades sustentáveis, porém no contexto dos complexos penitenciários, faz-se uso do método indutivo no que se refere à metodologia, com base em reconhecidas obras doutrinárias.

\section{A CRISE DA CIDADE PERANTE A DEGRADAÇÃO DO TECIDO SOCIAL NA GLOBALIZAÇÃO}

A cidade numa visão utópica deveria ser uma cidade ideal para todos, justa, com educação, saúde, entre outros, como bem descreve Platão quando se refere a Atlântida e Athenas descrita no livro "A República". Neste contexto, tem-se a cidade ideal na antiguidade, representada na figura da cidade grega, alicerçadas nos pilares de " [...] harmonia, segurança, evolução, completude, e institucionalização humana desde a urbanidade da cidade até a consciência do seu povo". (BLACKBURN, 2008; CARVALHO, 2015, p. 139).

Todavia, com o passar dos tempos e suas evoluções, muitas cidades ${ }^{5}$ se transformaram em metrópoles ${ }^{6}$, tornando-se assim grandes desafios aos governos e ao planeta. Estes problemas vêm permeados em sua grande maioria de concentração de pobreza, problemas ambientais, falta de saneamento e infraestrutura nas comunidades vulneráveis, entre outros. Esta somatização é acentuada na atualidade com a globalização do mundo moderno em decorrência da migração da "[...] ocupação urbana em níveis superiores ao crescimento da população", prejudicando assim o processo gradativo e ordenado da urbanização. (LEITE, 2012, p. 8-23; BALBIM, 2016, p.229).

Ademais, menciona-se que o processo da globalização vem agregado de transformações como tecnologia, economia, sociedade, entre outros, fazendo com que resultem nas mudanças que alteram os tempos contemporâneos. Mas, estas mutações levam as

\footnotetext{
${ }^{5}$ Como definição de cidades, numa perspectiva da teoria da realidade urbana, Henry Lefebvre em sua obra $\mathrm{O}$ Direito à Cidade, conceitua sendo a composição "[...] de fatos, de representações e de imagens emprestadas à cidade antiga (pré-industrial, pré-capitalista) mas em curso de transformação e de nova elaboração". (LEFEBVRE, 2006, p.21).

${ }^{6}$ Tem-se como definição de metrópole, "[...] uma cidade grande com tradição histórica muitas vezes centenária (Berlim) ou milenar (Lisboa, Roma), cuja população gira em torno de 5 milhões de habitantes. Na maioria dos casos, são capitais dos Estados que emergiram no final do século XIX, mas que já existiam como núcleos urbanos (sede do príncipe, cidade portuária ou comercial, cidade de produção e consumo, centro de cultura, entre outras funções) muitas vezes antes da Idade Média (Paris)". (FREITAG, 2006, p.154).
} 
cidades a passarem "[...] por um processo de polarização da força de trabalho e de perda de empregos dos setores tradicionais da economia". Consequentemente, a globalização que incorpora o processo de acumulação de economias de aglomeração, não é mais somente vista como produtora de economias de difusão. (LEITE, 2012, p. 86-87-92).

Salienta-se que a globalização não foi a única causadora das modificações do tecido social, muito pelo contrário, ela vem precedida do que chamamos de "mundo da mercadoria", na qual se tem como fator gerador a industrialização, isto é, "a prodigiosa expansão das trocas, da economia monetária, da produção mercantil, [...]”. Este resultado em seu processo de mudanças teve em seu curso, "a passagem do capitalismo comercial e bancário e da produção artesanal para a produção industrial e para o capitalismo concorrencial [...]," concorrendo desta maneira para fomentar o atual estágio da globalização. (LEFEBVRE, 2006, p.14).

Nas palavras de Bauman, "a globalização parece ter mais sucesso em aumentar o vigor da inimizade e da luta intercomunal do que em promover a coexistência pacífica das comunidades", levando assim a crise da cidade e consequentemente a deformação do tecido social. (BAUMAN, 2000, p.171).

“[...].Por conseguinte, a crise da cidade se liga não à racionalidade como tal, definível tomando-se por ponto de partida a tradição filosófica; essa crise se liga a formas determinadas da racionalidade: estatal, burocrática, econômica ou antes "economista", uma vez que o economismo é uma ideologia dotada de um aparelho. Esta crise da cidade faz-se acompanhar, quase em toda parte, por uma crise das instituições urbanas (...) devido à dupla pressão do Estado e da empresa industrial. Ora o Estado, ora a empresa, ora os dois (rivais, concorrentes, mas que muitas vezes se associam) tendem a se apoderar das funções, atributos, prerrogativas da sociedade urbana". (LEFEBVRE, 2006. p.84, aspas e colchetes no original).

Assim, a ruptura do tecido social foi observada no decorrer dos tempos em sua pior versão com os regimes totalitários e suas guerras sangrentas que se encaminharam a guerras mundiais. Como exemplo, tem-se a "[...] Revolução Francesa e da Revolução Comunista na Rússia, além do surgimento dos regimes fascista, na Itália e nazista, na Alemanha”. Todavia, como o passar dos séculos, isto é, "[...] a unificação do mercado mundial, a abolição dos privilégios pré-capitalistas e de sua fraterna desigualdade, a criação com o Estado de direito, de um regime de liberdade jurídica [...]" tem-se cada vez menos chances de um equilíbrio no 
tecido social, acentuada com a extração da mais-valia ${ }^{7}$ do assalariado. (ZUFFO, 2003, p.69; OLIVEIRA, 2004. p.87).

\footnotetext{
${ }^{7}$ Marx entende que o conceito de mais-valia é quando "O trabalhador é pago pela sua força de trabalho mediante um salário cujo valor tende a ser de mera sobrevivência, já que Ihe permite tão somente repor ou reproduzir sua força de trabalho”. O autor ainda distingue entre mais-valia absoluta e relativa. (CÁSSIA, 2001, p.63).
} 


\section{OS COMPLEXOS PRISIONAIS E SUAS RELAÇÕES NOS ESPAÇOS URBANOS DA CIDADE}

O Brasil tem atualmente a $3^{\mathrm{a}}$ maior população prisional do mundo, perdendo apenas para Estados Unidos e China. O quadro atual de encarcerados segundo atualização de Junho de 2017 do Levantamento Nacional de Informações Penitenciárias é de 726.354 apenados, divididos em 2.700 estabelecimentos prisionais. (BRASIL, 2019, p.7; CONSELHO NACIONAL DE JUSTIÇA, 2020).

Segundo o Instituto de Pesquisa sobre Políticas de Crime e Justiça (ICPR), que organiza o resumo Prisional Mundial, há um total de “[...] 10,74 milhões pessoas [...] mantidas em instituições penais em todo mundo, seja como detentos / prisão preventiva prisioneiros ou condenados e condenado". (ICPR, 2020).

Estes apenados que consequentemente são parte da degradação do tecido social, dividem-se em estabelecimentos prisionais que são verdadeiras cidades dentro das próprias cidades, os quais muitas vezes são desconhecidos pela sociedade. O Rio de Janeiro conta um total de 56 unidades prisionais, sendo o Complexo Penitenciário do Gericinó, em Bangu (RJ), um dos maiores do Estado, que é ocupado por $80 \%$ da população carcerária, ou seja, aproximadamente 42 mil presos. No Paraná, com um total de 224 estabelecimentos prisionais, o Complexo Penitenciário de Piraquara, situado na Região Metropolitana de Curitiba, possui cerca de 7 mil apenados, sendo estimado o maior do Estado. Em Brasília há o Complexo Penitenciário da Papuda que se encontra com aproximadamente 16 mil presos segundo dados do Departamento Penitenciário Nacional. Este quantitativo de pessoas localiza-se em apenas uma determinada área, separados na maioria das vezes por estruturas físicas próximas umas das outras, semelhante a conjunto de casas habitacionais. (BRASIL, 2019, p.9-10; CONSELHO NACIONAL DE JUSTIÇA, 2020).

Esta população que se encontra nos complexos prisionais do Brasil, além de se deparar na maioria das vezes com seus direitos violados, contribuem significativamente para a adversidade que agravam a crise da cidade e da degradação do tecido social. Menciona-se que estes problemas são acentuados ainda mais pela prisionização secundária, na qual exporta-se o modo de vida dos encarcerados a seus familiares, como descreve Megan Comfort (COMFORT, 2003). A autora retrata que 
“[...], a prisionização secundária é um fenômeno de assimilação das práticas prisionais pelos sujeitos que indiretamente mantém uma relação com a prisão, especialmente os familiares, os quais experienciam as práticas prisionais em razão dos novos modos de viver que a prisão impõe ao seu parente". (GONZAGA, 2013, p.20).

Outro fator importante neste contexto e esquecido na cidade urbana, refere-se ao assentamento urbano das famílias ao redor dos complexos prisionais de forma irregulares. Tal fato é derivado do intuito da permanência dos laços familiares e da diminuição das despesas no processo de visitação do apenado (GONZAGA, 2013. p.23). Estas ocupações geralmente em lugares denominados favelas ${ }^{8}$, gerados pela segregação sócio-espacial ${ }^{9}$, contrastam com a convivência dos trabalhadores urbanos de baixa renda e seus novos moradores, os familiares de presos, contribuindo significativamente para a desestruturação da cidade.

Nas palavras de Lefebvre,

\begin{abstract}
"Num período em que os ideólogos discorrem abundantemente sobre as estruturas, a desestruturação da cidade manifesta a profundidade dos fenômenos de desintegração (social, cultural). Esta sociedade, considerada globalmente, descobre que é lacunar. Entre os subsistemas e as estruturas consolidadas por diversos meios (coação, terror, persuasão ideológica) existem buracos, às vezes abismos. Esses vazios não provêm do acaso. São também os lugares do possível". (LEFEBVRE, 2006, p.115, colchetes no original).
\end{abstract}

Importante salientar que o assentamento destas pessoas situadas em bairros periféricos sem estrutura se intensificou nos anos de 1980 e 1990 no Brasil, decorrentes da política econômica recessiva da época. Assim, tem-se por diversos Estados do Brasil cinturões de favelas ao entorno dos complexos prisionais, característica da relação da proliferação da cidade e seus tecidos urbanos, que contrastam com os problemas da vida urbana. (HUGHES, 2004, pp. 93-102).

\footnotetext{
${ }^{8} \mathrm{O}$ termo favela num contexto genérico apresentado pelo Programa das Nações Unidas para Assentamentos Humanos (UNHABITAT), representa "[...]uma grande variedade de assentamentos humanos de baixa renda e com condições de vida precárias, que caracterizariam uma das várias manifestações da pobreza. Portanto, a questão de moradia está diretamente relacionada a condição de vida do indivíduo". (Programa Países Sustentáveis: Guia GPS Gestão Pública Sustentável, 2020, p. 22).

${ }^{9}$ Por segregação sócio-espacial entende-se: “[...] grado de proximidad espacial o de aglomeración territorial de las familias pertenecientes a un mismo grupo social, sea que éste se defina en términos étnicos, etarios, de preferencias religiosas o socioeconómicos, entre otras posibilidades. A qual é apresentada em três dimensões principais: (1) la tendencia de los grupos sociales a concentrarse en algunas áreas de la ciudad; (2) la conformación de áreas o barrios socialmente homogéneos; y (3) la percepción subjetiva que los residentes tienen de la segregación "objetiva" (las dos primeras dimensiones)". (SABATINI; CÁCERES; CERDA, 2001, vol. VIII).
} 


\section{CIDADES SUSTENTÁ VEIS E SUA CONTEXTUALIZAÇÃO NOS COMPLEXOS PRISIONAIS}

Com a problemática apresentada acima, têm-se soluções ainda a serem encontradas perante o contexto das cidades sustentáveis, visto que há um palco de transformações dramáticas a ser alcançado no maior desafio do século 21. Ademais, “[...] a agenda Cidades Sustentáveis ${ }^{10}$ é, assim, desafio e oportunidade únicas no desenvolvimento das nações. (LEITE, 2012, p. 8).

A Agenda 2030 de Desenvolvimento Sustentável”, constituída por 17 objetivos, desdobrados em 169 metas, já apresenta caminhos a serem seguidos, os quais “[...] visam resolver as necessidades das pessoas, tanto nos países desenvolvidos como nos países em desenvolvimento". Pode-se destacar o Objetivo de Desenvolvimento Sustentável de no 11, no que tange a "tornar as cidades e os assentamentos humanos inclusivos, seguros, resilientes e sustentáveis". (CENTRO DE INFORMAÇÃO REGIONAL DAS NAÇÕES UNIDAS PARA A EUROPA OCIDENTAL, 2020, p.2-22).

Destarte, o Brasil já reconhece em sua Constituição da República Federativa do Brasil o direito à cidade e à moradia, além de Leis urbanísticas que se apresentam como destaques na América Latina. Tem-se como referência no Brasil em nosso ordenamento jurídico o Estatuto da Cidade (Lei 10.257/2001), “[...] que instituiu uma série de ferramentas para que as municipalidades integrem os referidos instrumentos em suas estratégias de planejamento e gestão urbana" e, destaca-se em seu art. $2^{\circ}$ I, no qual faz menção expressa à sustentabilidade, referente à política urbana para o desenvolvimento das funções sociais da propriedade urbana, assegurando o "direito a cidades sustentáveis, entendido como o direito à terra urbana, à moradia, ao saneamento ambiental, à infraestrutura, [...], para as presentes e futuras gerações". (CONFEDERAÇÃO NACIONAL DE MUNICÍPIOS, 2017, p.98; BRASIL, 2020).

Assim, observa-se a necessidade da conjunção entre cidade e sustentabilidade urbana, afim "[...] de alinhar o desenvolvimento desses espaços com o respeito aos princípios da sustentabilidade", pois esta junção torna-se ponto crucial para o desenvolvimento

10 "O conceito de cidade sustentável reconhece que a cidade precisa atender aos objetivos sociais, ambientais, políticos e culturais, bem como aos objetivos econômicos e físicos de seus cidadãos. É um organismo dinâmico tão complexo quanto a própria sociedade e suficientemente ágil para reagir com rapidez às suas mudanças que, num cenário ideal, deveria operar em ciclo de vida contínuo, sem desperdícios [...]. (LEITE, 2012, p. 135). 
sustentável global. Todavia a cidade sustentável não se resume a aspectos de construções sustentáveis, pois, "ela deve incorporar parâmetros de sustentabilidade no desenvolvimento urbano público e privado". (LEITE, 2012, p. 132-133).

Nesse norte, Carlos Leite afirma que:

Nas cidades brasileiras, sustentabilidade urbana passa urgentemente pelo pilar social: alavancar a diversidade socioterritorial em nossas cidades é o desafio complexo e premente para promover cidades mais equilibradas nas formas como os diversos extratos populacionais ocupam o território comum e, portanto, de todos. Uma cidade mais justa e inclusiva no uso do território urbano é desafio dos governos e também pauta de toda a sociedade. (LEITE, 2012, p. 133).

Gomes e Zambam discorrem sobre a crise urbana e seus reflexos no presente e no futuro, visando a construção das cidades sustentáveis, ou seja;

Mas para que as cidades se tornem sustentáveis, necessita-se, por primeiro, despertar para novos valores. Nesse sentido, pode-se destacar enquanto forte aliado e importante elemento estratégico de fomento desse processo de implementação local de cidades sustentáveis a participação da sociedade e a necessária estruturação do poder local atrelado a iniciativas governamentais pautadas em estratégias socioambientais. A abertura do espaço público para a participação da sociedade faz os cidadãos fortalecerem o sentimento de pertencimento e de responsabilidade na gestão do seu ambiente de vida. (GOMES, 2011, p. 53).

Essa busca pelas cidades sustentáveis, as quais são importantes para recomposição do tecido social, há inúmeros desafios. Claro que em países em desenvolvimento o processo se torna ainda mais denso, visto que há problemas como transporte, infraestrutura, ambientais, segregação e acesso desigual ao urbano, que se somatizado tornam-se crescentemente polarizado e ambientalmente degradado. Nesta perspectiva, há por parte do Estado uma morosidade na gestão dos novos desafios apresentados pelas cidades sustentáveis, visto que o enxugamento da máquina estatal tem prejudicado de um modo geral as políticas públicas nos cenários futuros. (SANFELICI, 2016, v. 18, n. 37).

A construção de cidades sustentáveis em todas as suas dimensões, justas, equilibradas e inclusivas, tornou-se, além de um desafio para os governos e corporações, pauta de toda a Sociedade que tem ciência e comprometimento com os aspectos intergeracionais derivados de suas ações (SOUZA; ALBINO. 2018). 
Neste contexto Herzog menciona que "[...], as cidades brasileiras, em geral, estão longe de levar a biodiversidade urbana a sério (como deveriam, para sua sustentabilidade ambiental e resiliência [...]”. O retrocesso econômico e os lucros apresentados por instituições financeiras caminham em lados opostos no Brasil, direcionando-nos a um desmantelamento do nosso país e do planeta, pois, os recursos para a busca do “[...] desenvolvimento sustentável e equilibrado são esterilizados pelo sistema financeiro mundial". (HERZOG, 2013, p.97; DOWBOR, 2017, p.17).

Segundo Ladislau Dowbor,

Estamos destruindo o meio ambiente, a base natural sobre a qual a humanidade está condenada a sobreviver, esgotando os recursos, contaminando as águas, gerando caos climático, numa corrida desenfreada de produção e consumismo absurdo. Ao mesmo tempo, criou-se um precipício de desigualdades que só pode levar ao caos político, o que por sua vez trava as dinâmicas econômicas. Somos sistemicamente disfuncionais. (DOWBOR, 2017, p.268).

Após discorridos o texto deste capítulo, tem-se a seguinte pergunta: qual a contextualização dos complexos prisionais nas cidades sustentáveis? Segundo Jewkes e Moran, em seu artigo intitulado The paradox of the 'green' prison: Sustaining the environment or sustaining the penal complex, há uma "ausência de pesquisas empíricas sobre a relação entre sustentabilidade e encarceramento [...]". O que há conforme relata os autores, são pesquisas voltados a "[...] uma perspectiva crítica, radical ou abolicionista". (Jewkes e Moran, 2015, p.465).

Observa-se em alguns países como Reino Unido, Dinamarca, Noruega e Islândia e Estados Unidos que o tema sustentabilidade e sistema prisional já é evidenciado. Todavia, destaca-se no modelo islandês uma prisão futurista, voltada para uma arquitetura verde com estruturas de flores, isto é, para uma filosofia dos edifícios. Na Noruega baseado em um modelo clássico, segundo Bast $\varnothing y$, tem-se uma estrutura direcionada para a prisão ecológica, com propósito na percepção de compreensão e valores da ecologia. Já o Reino Unido, apenas uma unidade prisional, HMP Thameside, foi premiada com a "[...] classificação BREEAM Outstanding por sua nova Unidade Viva de quatro andares e 600 células, sendo altamente eficiente em energia. (JEWKES e MORAN, 2015, p.458). 
Skanska realiza construção verde porque é a coisa certa a fazer. Temos que mudar nossa sociedade para proteger o planeta para as gerações futuras, e, neste caso, o primeiro Prêmio BREEAM Prisons Outstanding do mundo demonstra que não estamos apenas 'no caso', mas muito no caminho em nossa jornada para Deep Verde. Este edifício excelente é o resultado de um trabalho mais inteligente - nossa equipe de design e nossa equipe de sustentabilidade e entrega de projetos realmente se envolvem entre si e com nosso cliente para eliminar ineficiências no edifício. O produto final é aquele que garante que nosso cliente (Ministério da Justiça) tenha um edifício com eficiência energética em um mercado altamente competitivo". (JEWKES e MORAN, 2015, p.458, aspas e colchetes no original).

Estes modelos se divergem do modelo americano, que tem como foco o impacto ambiental e os investimentos dispendidos nas próprias instalações prisionais, que se menciona quase quadruplicou nas últimas duas décadas. Os altos gastos de recursos e com as questões ambientais pós-Kyoto, a agenda da sustentabilidade foi fomentada nas prisões dos Estados Unidos da América. Neste contexto, o Departamento de Justiça dos EUA tem levado aos Departamentos de Prisões Federal estratégias, boas práticas e ferramentas no que tange a “"...] sustentabilidade em instalações correcionais e fornecer recomendações aos profissionais na aplicação essas informações para suas próprias instalações”. A prisão do Washington Departamento Estadual de Correções, que além de sua prisão verde (estrutura), foca na educação ecológica dos presos, com o intuito de fornecer uma educação e treinamento. Esta imersão que é propiciada ao apenado, além de propiciar o cultivo, construção e criar funções nas prisões sustentáveis, fomenta uma profissão técnica desenhada para o crescente setor verde da economia. (MORAN e JEWKES, 2014).

No Brasil não existem trabalhos específicos entre a prisionização secundária, favelização, ODS 11 e cidades sustentáveis. Neste contexto, há estudos intrínsecos em temas independentes que contribuem sim para a problemática, todavia não correlacionados totalmente. Um exemplo claro é o trabalho de Gonzaga no qual menciona que a cultura que abrange o modus operandi dentro do cárcere e levada a seus familiares para o ambiente externo, faz com que a "[...] a informalidade da organização e manifestações socias de seus membros" seja duplicada na sociedade. Todavia, não existe estudos de seus reflexos na dimensão da prisionização e a favelização. (GONZAGA. 2013. p.20).

Um estudo que apresenta correlações é apresentado pelo IPEA, no que tange as Metas Nacionais dos Objetivos de Desenvolvimento Sustentável. Segundo o Ipea, através de uma proposta para "adequação das metas globais da Agenda 2030 para o Desenvolvimento 
Sustentável à realidade brasileira", o órgão apresenta propostas na ODS\#11, no que tange as favelas, denominada no presente trabalho como assentamentos precários, visando uma inclusão destas áreas mais sustentáveis e inclusivas. Já trata do aspecto prisional, mas num âmbito de indicadores, com propósito da ODS\#16, especificamente a meta 16.3, porém, voltado para "fortalecer o Estado de Direito e garantir o acesso à justiça às pessoas envolvidas em conflitos, especialmente àquelas que se encontram em situação de vulnerabilidade”. As cidades sustentáveis encontram-se especificamente na ODS\#11. Todavia, a prisionização não aparece no referido texto, mas, pode-se observar sua ligação em diversos aspectos, em específico a ODS\#10, entre outras. (IPEA, 2018).

Todavia, em Santa Catarina há projetos isolados no interior dos complexos prisionais que já contribuem com a perspectiva das cidades sustentáveis, porém, não inseridas no contexto geral da cidade sustentável. Conforme apresentado pela Secretaria de Administração Prisional e Socioeducativa inúmeras soluções inovadoras dentro dos cárceres, que vão desde plantação de verduras na penitenciária de Chapecó, feira de produtos agrícolas à comunidade juntamente com compostagem e plantação da uva-bordô em Curitibanos, captação da água da chuva no Complexo Prisional de Canhanduba - Itajaí, a substituição de copos descartáveis por reutilizáveis para os servidores das unidades prisionais, cultivo de hortifrúti na região de Rio do Sul entre outros. (SECRETARIA DE ESTADO DA ADMINISTRAÇÃO PRISIONAL E SOCIOEDUCATIVA, 2020).

Estas iniciativas vão ao encontro do esverdeamento das correções (The Greening of Corrections) apresentado pelo relatório publicado pelo Instituto Nacional de Correções, pelo Departamento de Justiça dos EUA, Federal Bureau of Prisões, a fim de criar um sistema sustentável. Segundo o presente documento, a ideia principal é subsidiar seus gestores com práticas, orientações e estratégias voltados para a sustentabilidade do sistema prisional. (NATIONAL INSTITUTE OF CORRECTIONS, 2011).

Constata-se em ambos os países, Brasil (especificamente em Santa Catarina) e os Estados Unidos (EUA) uma preocupação em preparar o apenado profissionalmente com técnicas sustentáveis. Em Santa Catarina, conforme já relatado, os presos são inseridos na colheita, plantação, compostagem e a captação de água. Nos EUA tem-se a terminologia treinamento do colarinho verde. Isto nada mais é do que propor "[...] a terapia com prisioneiros com base na natureza [...]". (NATIONAL INSTITUTE OF CORRECTIONS, 2011). 
Por exemplo, o Estado de Washington não apenas adota uma abordagem holística da sustentabilidade, implementando os tipos de medidas de 'edifícios verdes' em relação à energia, água e resíduos descritos anteriormente, mas também lançou o 'Projeto Prisões Sustentáveis', que fez um esforço conjunto fornecer treinamento "de colarinho verde" e terapia baseada na natureza a prisioneiros envolvidos em "tarefas de cultivo, triagem, construção e cultivo", através dos quais": (JEWKES e MORAN, 2015, p.460).

Ainda neste contexto, conforme menciona o Departamento de Justiça dos EUA, os internos vão poder:

[..] reunir habilidades profissionais e técnicas que podem se traduzir em carreiras no crescente setor verde da economia. Os programas de manutenção de prisões estão integrando elementos verdes: mais de 60 presos envolvidos no Projeto Prisões Sustentáveis estão adquirindo habilidades em horticultura, compostagem e apicultura. (NATIONAL INSTITUTE OF CORRECTIONS, 2011).

Neste viés, não podemos apenas apresentar as boas práticas num comparativo com outros países. É necessário observar a prisionização secundária que remete ao extramuros dos complexos prisionais que refletem no discurso do contexto geral da cidade sustentável como um todo. Bem, se analisar o contexto da distribuição de riquezas, associado ao desmantelamento estatal, as mudanças das políticas sociais e econômicas, levando a exclusão social, tem-se uma ruptura considerável no tecido social que consequentemente infere em um aumento significativo na massa carcerária. Estes fatores já descritos no capítulo anterior vão trazer sérios problemas na construção da tão almejada cidade sustentável, não só pelas estruturas prisionais e seus reflexos, mas pela prisionização secundária e suas consequências.

Como bem afirma Noam Chomsky, “A desigualdade acarreta muitas consequências. Não é somente extremamente injusta em si mesma, mas também tem consequências altamente nocivas para a sociedade como um todo". Este mesmo entendimento é observado por Muhammad Yunus, quando o mesmo retrata os problemas sociais contemporâneos ocasionados pela desigualdade avassaladora da má distribuição de renda concentrada por uma pequena parcela da população. $\mathrm{O}$ autor descreve os problemas do sistema econômico e sua atual transformação que ameaça o progresso humano levando a falência da democracia, pois o poder na mão de poucos fomenta uma política voltada as elites que a utiliza em seu benefício. (CHOMSKY, 2017, p.21; YUNUS, 2018). 
Assim, para a resposta questionada acima, não basta apenas a restruturação do tecido urbano dos complexos prisionais na perspectiva das cidades sustentáveis. As políticas públicas de segurança não podem se limitar apenas a complexidade das fronteiras que se encontram os espaços prisionais e o urbano. A questão da inserção das estruturas prisionais dentro das cidades sustentáveis vão além, ou seja, atingem as esferas da política pública, redução dos índices de violência urbana, relação jurídica entre Estado e preso, planejamento urbano, sociedade, reinserção do apenado no meio social, questões de estruturas prisionais sustentáveis (com a utilização de painéis fotovoltaicos, reaproveitamento de água, plantação de verduras e hortaliças, utilização de jardins filtrantes, compostagem, etc.), entre outras situações.

Outro fator a ser efetivado e de alta adversidade tange a questão da desigualdade social e economica não somente aos familiares dos presos, mas a toda a população em prol das cidades sustentáveis, a fim de beneficiar as atuais gerações e futuras. Segundo os autores Wang, Lall e Mata, a favelização no Brasil em suas cidades são decorrência de algumas particularidades apontadas na desigualdade de renda e crescimento econômico. Todavia, segundo os autores em um estudo do processo de favelização das cidades brasileiras no período entre 1980 e 2000, a melhor distribuição de renda pode corroborar com a diminuição das classes menos favorecidas. (IPEA, 2007, p.14).

Crescimento econômico pode resultar na atração de migrantes pobres, sugerindo, então, um aumento das favelas. Mas as evidências mostram que o crescimento econômico das cidades cria condições para a absorção desses migrantes e para a redução agregada do número de habitantes em favelas. (IPEA, 2007, p.62).

Por fim, entende-se que a desarmonia entre as políticas públicas e penitenciária precisam se reinventar para que os complexos prisionais sejam inseridos de forma planejada nos espaços urbanos contribuindo de forma significativa com as cidades sustentáveis. Muitas soluções já se encontram em atividade em Santa Catarina, porém de formas dispersas no Estado e sem políticas públicas para seu fomento. Com relação às questões da favelização acentuada pela prisionização secundária, devem-se repensar as prioridades destacadas no regime capitalista e, até onde apresenta respostas de seus impactos e efeitos perante a dinamicidade das cidades sustentáveis. A construção de espaços que visem ao convívio social, à integração, às trocas sociais, à diminuição das desigualdades e da exclusão social, 
conjugados ao respeito aos recursos naturais, são pautas indiscutíveis de governantes comprometidos com o processo democrático no país.

\section{CONSIDERAÇÕES FINAIS}

O presente trabalho teve o intuito de abordar uma lacuna na literatura no que tange a cidades sustentáveis e complexos prisionais no Brasil. Esta deficiência pode ser comparada no artigo The paradox of the 'green' prison: Sustaining the environment or sustaining the penal complex, dos autores Jewkes e Moran. Estes ainda complementam afirmando que o destaque fica pontualmente no quesito a crítica, radicalismo ou abolicionismo voltados para os complexos prisionais, sem qualquer paralelo com o novo desafio da sociedade, ou seja, as cidades sustentáveis. (Jewkes e Moran, 2015, p.465).

Todavia, observa-se experiências já existentes em países como Reino Unido, Dinamarca, Noruega e Islândia e Estados Unidos. A Islândia apresenta uma estrutura voltada para uma arquitetura verde. Já a Noruega pontua um olhar voltado na percepção de compreensão e valores da ecologia. Ambos os modelos vêm na contramão dos americanos, pois, este salienta o aspecto ambiental voltado para a redução de custos das instalações prisionais, pois há severas críticas por parte da sociedade nos gastos do sistema penitenciário.

Fazendo-se um paralelo com o Brasil, observa-se que não há nenhuma proposta entre os 2.700 estabelecimentos prisionais brasileiros que se assemelhem aos modelos da Reino Unido, Islândia ou Noruega. Porém, há um modelo em Santa Catarina que vai ao encontro da proposta dos Estados Unidos, mas com raríssimos estudos que correlacionem com os americanos e sua aplicabilidade tanto na questão sustentável, quanto nas vantagens para os benefícios das cidades sustentáveis. (BRASIL, 2019, p.7; CONSELHO NACIONAL DE JUSTIÇA, 2020).

Santa Catarina é um dos raros Estados da federação que já se destaca na perspectiva das cidades sustentáveis, contribuindo com inúmeras soluções inovadoras dentro dos cárceres, que vão desde plantação de verduras na penitenciária de Chapecó, feira de produtos agrícolas para a comunidade juntamente com compostagem e plantação da uva-bordô em Curitibanos, captação da água da chuva no Complexo Prisional de Canhanduba - Itajaí, a substituição de copos descartáveis por reutilizáveis para os servidores das unidades prisionais, cultivo de 
hortifrúti na região de Rio do Sul, entre outros. (SECRETARIA DE ESTADO DA ADMINISTRAÇÃO PRISIONAL E SOCIOEDUCATIVA, 2020).

Porém, há a necessidade de estudos mais aprofundados e pontuais para fazer uma correlação com a eficácia da sustentabilidade nos complexos prisionais. Tal necessidade se faz necessária em virtude das novas reformulações que apresentam soluções inovadoras a sociedade, como prisões verdes, que almejam na verdade interesses corporativos no encarceramento em massa.

Tem-se ainda um agravante que não é percebido no contexto das cidades sustentáveis, que é oriundo dos complexos prisionais, isto é, a prisionização secundária. Trata-se da exportação do modo de vida dos encarcerados a seus familiares, que se encontram geralmente em favelas situados em cinturões ao entorno das áreas prisionais, que se proliferam ainda mais pela segregação sócio-espacial, contribuindo para os problemas da vida urbana que contrastam com as cidade e seus tecidos urbanos.

Por fim, observa-se que há nos complexos prisionais em Santa Catarina boas práticas que podem contribuir de forma significativa no contexto das cidades sustentáveis. Porém, fazse necessário um estudo aprofundado com dados estatísticos e pesquisa em campo que comprovem sua verdadeira eficiência, refletindo em todo o Brasil.

\section{REFERÊNCIAS}

BALBIM, Renato. Cidade e movimento: mobilidades e interações no desenvolvimento urbano. In: BALBIM, Renato; KRAUSE, Cleandro; LINKE, Clarisse Cunha. - Brasília: Ipea: ITDP, 2016.

BLACKBURN, Simon. A República de Platão: uma biografia.Tradução, Roberto Franco Valente; revisão técnica, Danilo Marcondes. — Rio de Janeiro: Jorge Zahar Ed., 2008.

BRASIL. Ministério da Justiça e Segurança Pública - Departamento Penitenciário Nacional. Levantamento Nacional de informações penitenciárias INFOPEN- junho 2017. MOURA, Marcos Vinícis (org.). Brasília: 2019. Disponível em:

$<$ http://depen.gov.br/DEPEN/depen/sisdepen/infopen/relatorios-sinteticos/infopen-jun-2017rev-12072019-0721.pdf> Acesso em: 06 de fev. 2020.

Lei 10.257, de 10 de julho de 2001. Regulamenta os arts. 182 e 183 da Constituição Federal, estabelece diretrizes gerais da política urbana e dá outras providências. 
Diário Oficial [da] República Federativa do Brasil, Brasília, DF, 11 de jul. 2001. Disponível em: Acesso em 09 de fev. 2020.

CARVALHO. Tiago Nascimento de Carvalho. O Ideal do Príncipe e a Cidade Ideal: reflexões sobre o mundo antigo em diálogo como os fvndamenta da construção de Brasília. Tese (Estudos Clássicos) - Universidade de Coimbra. 2015.

CÁSSIA, Rita de. Sociologia: consensos \& conflitos. Org. por RM de Cássia da Silva Oliveira Ponta Grossa, Editora: UEPG, 2001.

CENTRO DE INFORMAÇÃO REGIONAL DAS NAÇÕES UNIDAS PARA A EUROPA OCIDENTAL. Guia sobre Desenvolvimento Sustentável 17 objetivos para transformar o nosso mundo. 2016. Disponível em:

$<$ https://www.unric.org/pt/images/stories/2016/ods_2edicao_web_pages.pdf > Acesso em 07 de fev. 2020.

CHOMSKY, Noam. Réquiem para o sonho americano [recurso eletrônico]: os dez princípios de concentração de riqueza e poder. Tradução Milton Chaves de Almeida. - 1 ed. Rio de Janeiro: Bertrand Brasil, 2017.

COMFORT, Megan. In teh Tube at San Quentin. The 'Secondary Prisionization' of women visiting inmates. Journal of Contemporary Ethnography, Vol 32 (1): 77-107. 2003.

CONFEDERAÇÃO NACIONAL DE MUNICÍPIOS - CNM. Guia para Integração dos Objetivos de Desenvolvimento Sustentável nos Municípios Brasileiros - Gestão 20172020 - Brasília, DF: CNM, 2017.

CONSELHO NACIONAL DE JUSTIÇA. Dados de inspeções de estabelecimentos penais. Geopresídios é uma Radiografia do Sistema Prisional. Disponível em: < https://www.cnj.jus.br/inspecao_penal/gera_relatorio.php?tipo_escolha=comarca\&opcao_esc olhida=25\&tipoVisao=estabelecimento> Acesso em: 06 de fev. 2020.

Dados de inspeções de estabelecimentos penais. Geopresídios é uma Radiografia do Sistema Prisional. Disponível em: 〈https://www.cnj.jus.br/inspecao_penal/mapa.php> Acesso em: 06 de fev. 2020.

DOWBOR, Ladislau. A era do capital improdutivo: Por que oito famílias tem mais riqueza do que a metade da população do mundo. São Paulo: Autonomia Literária, 2017. p.17.

FREITAG, Barbara. Teoria da cidade. Campinas, SP: Papirus, 2006. 
GOMES, Daniela, ZAMBAM, Neuro José. O desafio da sustentabilidade urbana. Revista Brasileira de Direito. ISSN 2238-0604. Passo Fundo, vol. 7, n. 1, jan-jun, 2011, p. 39-60, p. 53.

GONZAGA. Vanessa Portes Galvão. À Sombra do Encarceramento: o entrono das prisões. Tese (Tese em História) - Universidade Federal de Uberlândia, 2013. 216 p.

HERZOG, Cecilia Polacow. Cidades para todos: (re) aprendendo a conviver com a natureza. - I. ed. - Rio de Janeiro: Mauad X: Inverde, 2013.

HUGHES, Pedro Javier Aguirre. Segregação socioespacial e violência na cidade de São Paulo: referências para a formulação de políticas públicas. In: São Paulo em Perspectiva. São Paulo: 18(4), 2004.

ICPR. Institute for Criminal Policy Research. World Prison Brief. Highest to Lowest Prison Population Rate. Disponível em:

<https://www.prisonstudies.org/sites/default/files/resources/downloads/wppl_12.pdf > Acesso em 06 de fev. 2020.

IPEA - Instituto de Pesquisa Econômica Aplicada. Ensaios de economia regional e urbana. Organizadores: Alexandre Xavier Ywata Carvalho [et al.]. Brasília: Ipea, 2007.

ODS - Metas Nacionais dos Objetivos de Desenvolvimento Sustentável: Proposta de adequação. Coordenação: Cláudio Passos de Oliveira. Brasília: Ipea, 2018. Disponível em: < http://www.ipea.gov.br/portal/publicacoes>. Acesso em 19 de fev. 2020.

JEWKES, Yvonne; MORAN, Dominique. The paradox of the "green' prison: Sustaining the environment or sustaining the penal complex? Theoretical Criminology. 2015. doi: $10.1177 / 1362480615576270$.

LEFEBVRE, Henry. O Direito à Cidade. Trad. Rubens Eduardo Frias, $4^{\mathrm{a}}$ Ed. São Paulo: Centauro, 2006.

LEITE, Carlos. Cidades sustentáveis, cidades inteligentes: desenvolvimento sustentável num planeta urbano. Porto Alegre: Bookman, 2012.

MORAN, Dominique, JEWKES, Yvonne. "Green" prisons: rethinking the "sustainability" of the carceral estate. Published by Copernicus Publications for the GeographischEthnographische Gesellschaft Zürich \& Association Suisse de Géographie. Disponível em: <www.geogr-helv.net/69/345/2014/>. doi:10.5194/gh-69-345-2014. Acesso em: 14 de fev. 2020. 
NATIONAL INSTITUTE OF CORRECTIONS. U.S. Department of Justice. The Greening of Corrections: Creating a Sustainable System. 2011. Disponivel em:

<https://info.nicic.gov/nicrp/system/files/024914.pdf >. Acesso em 14 mar. de 2020.

OLIVEIRA, Nelson. Neocorporativismo e Política Pública: um estudo das novas configurações assumidas pelo Estado. Edições Loyola. 2004, apud Fioirito, 18 p.

PONTIFÍCIA UNIVERSIDADE CATÓLICA DE SÃO PAULO. Programa Países

Sustentáveis: Guia GPS Gestão Pública Sustentável. Disponível em:

<https://www.pucsp.br/catedraignacysachs/downloads/pac3adses_sustentc3a1veis_gps.pdf >.

Acesso em: 07 de fev. 2020.

SABATINI, Francisco; CÁCERES, Gonzalo; CERDA, Jorge. Segregación residencial en las principales ciudades chilenas: Tendencias de las tres últimas décadas y posibles cursos de acción. In: Scripta Nova. Revista Eletrônica de Geografia y Ciências Sociales. Barcelona: Universidad de Barcelona, 17 de setembro de 2001, vol. VIII, num. 146(123). Disponível em: <http://www.ub.es/geocrit/sn/sn-146(123).htm> Acesso em 07 de fev. 2020.

SANFELICI, Daniel. A centralidade das aglomerações metropolitanas na economia globalizada: fundamentos econômicos e possibilidades políticas. Cadernos Metrópole, São Paulo, v. 18, n. 37, p. 623-646, dez. 2016. Disponível em:

$<$ http://www.scielo.br/scielo.php?script=sci_arttext\&pid=S2236-99962016000300623

$\& \operatorname{lng}=$ pt\&nrm=iso $>$ Acesso em: 09 de fev. 2020.

SECRETARIA DE ESTADO DA ADMINISTRAÇÃO PRISIONAL E

SOCIOEDUCATIVA. Penitenciária Agrícola de Chapecó irá fornecer produtos de sua horta para a Prefeitura do Município. Departamento de Administração Prisional- DEAP. Disponível em: < http://www.sap.sc.gov.br/index.php/noticias/todas-as-noticias/8735penitenciaria-agricola-de-chapeco-ira-fornecer-produtos-de-sua-horta-para-a-prefeitura-domunicipio> Acesso em: 14 de fev. 2020.

Feira da Penitenciária da Região de Curitibanos vende produtos agrícolas à comunidade. Departamento de Administração Prisional- DEAP. Disponível em: < http://www.deap.sc.gov.br/index.php/noticias/729-feira-da-penitenciaria-da-regiao-decuritibanos-vende-produtos-agricolas-a-comunidade> Acesso em: 14 de fev. 2020.

Penitenciária da Região de Curitibanos estima colheita de 3 mil quilos de uva bordô. Departamento de Administração Prisional- DEAP. Disponível em: < http://www.deap.sc.gov.br/index.php/noticias/735-penitenciaria-da-regiao-de-curitibanosestima-colheita-de-3-mil-quilos-de-uva-bordo> Acesso em: 14 de fev. 2020.

Deap entrega copos reutilizáveis para os servidores das unidades prisionais.

Departamento de Administração Prisional- DEAP. Disponível em: 
$<$ http://www.deap.sc.gov.br/index.php/noticias/741-deap-entrega-copos-reutilizaveis-para-osservidores-das-unidades-prisionais> Acesso em: 14 de fev. 2020.

Presídio de Rio do Sul começa colheita de alimentos da horta da unidade.

Departamento de Administração Prisional- DEAP. Disponível em: < http://www.deap.sc.gov.br/index.php/noticias/733-presidio-de-rio-do-sul-comeca-colheita-dealimentos-da-horta-da-unidade-2> Acesso em: 14 de fev. 2020.

SOUZA, Maria Cláudia da Silva Antunes de. ALBINO, Priscilla Linhares. Cidades Sustentáveis: ultrapassando as estruturas físicas para atingir a Sustentabilidade Social. In: Direito e sustentabilidade III [Recurso eletrônico on-line] organização CONPEDI/ UNISINOS Coordenadores: Raquel Von Hohendorff; Veronica Lagassi; Fernanda Sell de Souto Goulart Fernandes. - Florianópolis: CONPEDI, 2018.

YUNUS, Muhammad. Um mundo de três ceros. La nueva economia de pobreza cero, desempleo cero y emisiones netas de carbono. Traducción, Pablo Hermida Lazcano. Barcelona: Editorial Planeta. Paidós, 2018.

ZUFFO, João Antônio. A sociedade e a economia no novo milénio: os empregos e as empresas no turbulento alvorecer do século XXI, livro 2: macroeconomia e empregos / João Antônio Zuffo. - Barueri, SP: Manole, 2003.

ZYGMUNT Bauman. Modernidade Líquida. Tradução: Plínio Dentzien - Editora: Rio de Janeiro. Título original: LiquidModerniiy. Tradução autorizada da edição inglesa publicada em 2000 por Polity Press, de Oxford, Inglaterra.

Capitalismo parasitário: e outros temas contemporâneos. Tradução Eliana

Aguiar. - Rio de Janeiro: Jorge Zahar Ed., 2010. p.8. 